\title{
Amazon's cloud on the healthcare horizon
}

\author{
A new venture from Amazon, JP Morgan and Berkshire Hathaway has US healthcare in its crosshairs. It may also \\ offer opportunities for innovators in health IT and digital medicine.
}

A $t$ the end of January, three of the world's most powerful CEOs announced a new venture to take aim at the bloated US healthcare system. The not-for-profit, launched by Jeff Bezos of tech behemoth Amazon, Jamie Dimon of US bank JP Morgan Chase and Warren Buffett of the Berkshire Hathaway conglomerate, seeks to implement technology solutions that will deliver "high-quality and transparent healthcare at a reasonable cost." Initially, the focus is on saving the three companies 20\% of the money they spend on healthcare plans for their $\sim 1.2$ million-strong combined workforce. In a sense, it is a pilot project. But if the new venture achieves cost savings and improves patient outcomes, it may turn out to be an alpha test for a prototype that could be adopted by other employers. Unlike previous attempts to fix US healthcare, this bid is led by a corporate threesome that wields enough financial resources, technological prowess and business adroitness to make a difference and make that difference profitably. Value attribution, financial arbitrage and shortening of the trading chain will be key in disrupting the current entrenched system and reorienting its administrative and fiscal dependencies. Biotech companies would do well to watch closely how the pilot scheme unfolds.

For now, the experiment looks unlikely to place the biopharmaceutical sector at the center of any turmoil. Even biotech's clientele, the large pharmaceutical firms, will be, as product innovators and producers, at the periphery of the immediate storm. However, a health market that defines value in a more logical manner may define different goals for health innovators. Innovating for value is quite distinct from innovating for profitability. Bringing life sciences closer to end-users, if that is what the new scheme achieves, will reduce waste-oriented rationales and disentangle the prevailing model of market protectionism. Eventually, new opportunities in health IT, digital medicine and drug development may emerge.

US healthcare costs accounted for 18\% (\$3.3 trillion) of US gross domestic product in 2017. Consultants McKinsey \& Co. estimate $\sim 900$ billion of that number goes into waste, fraud, abuse, misuse and avoidable medical costs. As Berkshire's Buffet puts it: “The ballooning costs of healthcare act as a hungry tapeworm on the American economy." Large employer-sponsored health plans have seen an average annual increase of $\sim 3 \%$ over the past 5 years, according to HR consultancy Mercer, with a $4.3 \%$ increase expected in 2018 . Two years from now, another threat looms for employers: a $40 \%$ excise (Cadillac) tax (from the Affordable Care Act) on high-value group health plans, likely to affect $31 \%$ of all US companies with 500 or more employees.

When groups like Amazon, JP Morgan and Berkshire-or indeed any US employer-look hard look at healthcare, they do not like what they see.

Most (90\%) of the ballooning costs come from health practioners and hospitals. But drug and device makers are part of the problem. Price hikes for old drugs well above inflation, backroom deals with pharmacy benefit managers (PBMs), pay-for-delay arrangements for generic drugs and the manipulation of drug shortages all drive up prices. Even so, many of the premiums for innovative and life-changing products are warranted, and the majority of pricing problems arise due to the proliferation of middlemen and lack of transparency in how deals are done, rather than because industry is morally corrupt. Costs are inflated by manufacturers to both feed themselves and provide a cut for their 'cuckoo children'-PBMs, insurers and wholesalers.

Exactly how the new venture will tackle these problems remains unclear; Warren Buffett says the new entity "does not come to this problem with answers."

One place it could start is with the PBMs. OptumRX, Express Scripts and CVS Caremark control $80 \%$ of the market and increase their profits pocketing rebates and increasing costs to employers and patients. By negotiating directly with device and drugmakers, the new entity could get a better deal for patients. This alone could create a seismic shift in healthcare economics, and a shift in trust, too, if it was done transparently, rather than behind closed doors (as PBMs and manufacturers currently operate).

Equally, the new venture might compete directly with drug and device wholesalers like McKesson, AmerisourceBergen and Cardinal Health. Late last year, Amazon applied for wholesale pharmacy licenses in a dozen states (investment bank SG Cowen notes that some of these have now lapsed), ostensibly to extend the company's medical device offerings. As yet, Amazon has announced no plan to distribute prescription drugs.

But perhaps the key ingredient the new venture brings is scale. Having 1.2 million employees between the three companies already represents significant bargaining power. And Amazon brings the most important scaling tool of all: online platforms for engaging customers. Amazon Web Services' cloud offerings could stream data from employees (with appropriate confidentiality protection) through a state-of-the-art IT infrastructure supporting wellness, prevention and treatment platforms with integrated digital health apps. Suitably routed, the data could be shared with healthcare providers, practitioners and caregivers.

For employees, Amazon's Alexa could offer health advice. Already the tech giant has partnered with Boston Children's Hospital, the Mayo Clinic and Web MD to develop Alexa health information services (the system can already book telemedicine appointments via Teladoc). Perhaps voice analysis through Alexa might find other uses to monitor behavior, cognitive performance and mental health status.

That imagined picture is a very different prospect from the ossified and fragmented US health system of today, with its strata of billable lines and obsolescent IT systems. But for this not to be just another breathlessly hyped 'disruption' in healthcare, the pilot scheme must show it can bring down costs as well as improve care. If it does both, the biotech community just might find itself playing in a very different healthcare ecosystem in the years to come. 